\title{
Patents, profit and the public good: the case of a 19th-century artificial limb manufacturer
}

$\mathrm{M}$ édecins Sans Frontières recently expressed concern that patent provisions in the Trans-Pacific Partnership would make it harder for people to access affordable drugs. ${ }^{1}$ The challenge of balancing profit with the public good is a familiar one in the history of medicine. For example, the 1847 code of ethics of the American Medical Association (AMA) deemed it "derogatory to professional character ... for a physician to hold a patent for any surgical instrument, or medicine."2 Patents, in the estimation of the AMA, put profit ahead of patients and interfered with the belief - often referred to as the "sharing norm" - that information and innovations should circulate freely within the profession. The Canadian Medical Association included the same clause in its first code of ethics in 1868, and in both countries the prohibition stayed in place until the 20th century.

In some instances, creative workarounds could help balance patents, ethics and the public good. In 1922, for example, the University of Toronto set up a committee to manage insulin patents and licences to serve the best interests of patients. ${ }^{3}$ Starting in 1923, the government of Canada also facilitated various forms of compulsory licensing to ensure affordable pharmaceuticals, an approach that stayed in place until the 1980s and took an international humanitarian turn with the Jean Chrétien Pledge to Africa Act in 2004. ${ }^{4}$

In mid-19th-century America, artificial limb manufacturer B. Frank Palmer (1824-1898) found that, with the right spin, patenting itself could help him balance profitable monopoly with an apparent dedication to benevolent philanthropy and, thus, elevate him to the status of a respected and munificent professional. Palmer lost a leg in a childhood accident, and in 1846, without any for-

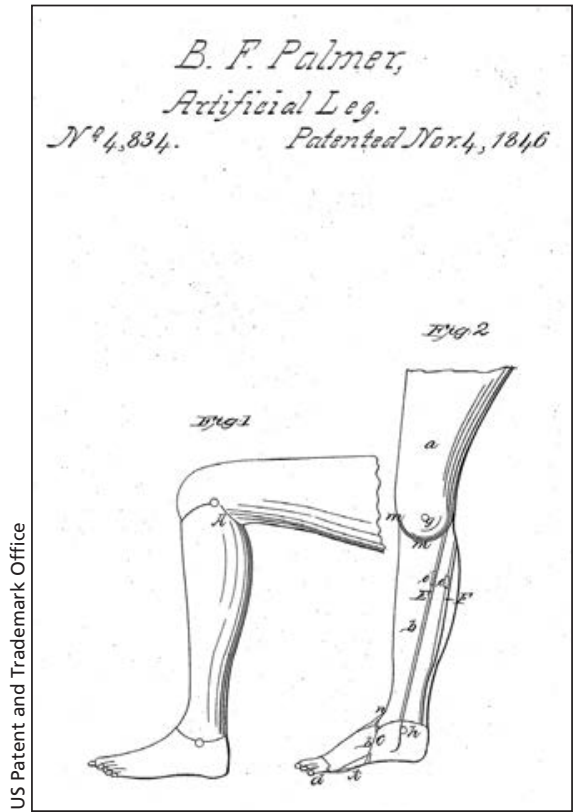

Figure 1: Drawing from B. Frank Palmer's artificial limb patent (1846; US Patent no. 4,834).

mal medical training, he patented the first artificial limb in the United States, which he went on to sell from shops in Boston, New York and Philadelphia (Figure 1). He patented several improvements to the prosthesis and even took it to London's Great Exhibition in 1851 (Figure 2). By 1859, the young entrepreneur had already sold more than 3000 "Palmer's Patent Legs."

In addition to being a keen businessman and self-promoter, Palmer was eager to win the approval of orthodox medical practitioners and respect for his own occupation. He depicted himself as a "Surgeon-Artist," working in parallel with the doctor, and he boasted that he and his partners had visited medical schools and hospitals, and trained in anatomy and surgery in the hope of "ultimately placing the Profession on a level with the highest - a position to which its importance entitles it." ${ }^{5}$ The provision of artificial limbs was not exactly medicine, but, in Palmer's mind, it was deserving of similar professional prestige.

How could Palmer reconcile his claim to professionalism with his patents, which he protected aggressively against infringement by rival manufacturers? The answer was clearly articulated in 1860, when Palmer applied for a patent extension. Until 1861, US patents lasted 14 years, with the Patent Act of 1836 offering the possibility of an additional 7 years. The extension would be granted if, "having due regard to the public interest," the patentee had failed to obtain "a reasonable remuneration for the time, ingenuity, and expense" of inventing the item and introducing it into use. ${ }^{6}$ Without this chance for additional compensation, the patent system could hardly be said to be doing its job of incentivizing invention and innovation.

Palmer and his lawyer, Charles Stansbury, worked hard to ensure that their application was successful. The patent extension file, now housed at the US National Archives in Maryland, is a box stuffed with promotional brochures, supporting testimony and a careful tally of Palmer's expenses and profits. The most compelling part is Stansbury's 21-page Argument in Behalf of the Extension of the Patent, which Palmer - somewhat unusually — arranged to have printed. ${ }^{7}$ After showing the artificial limb's novelty and utility, as well as Palmer's modest remuneration compared with the product's monetary value to American society, Stansbury launched into the heart of his argument: the public interest. Palmer's patent, he explained, ensured that the limb would be produced at a consistently high quality and by only Palmer himself or his reputable assignees. Without the patent 


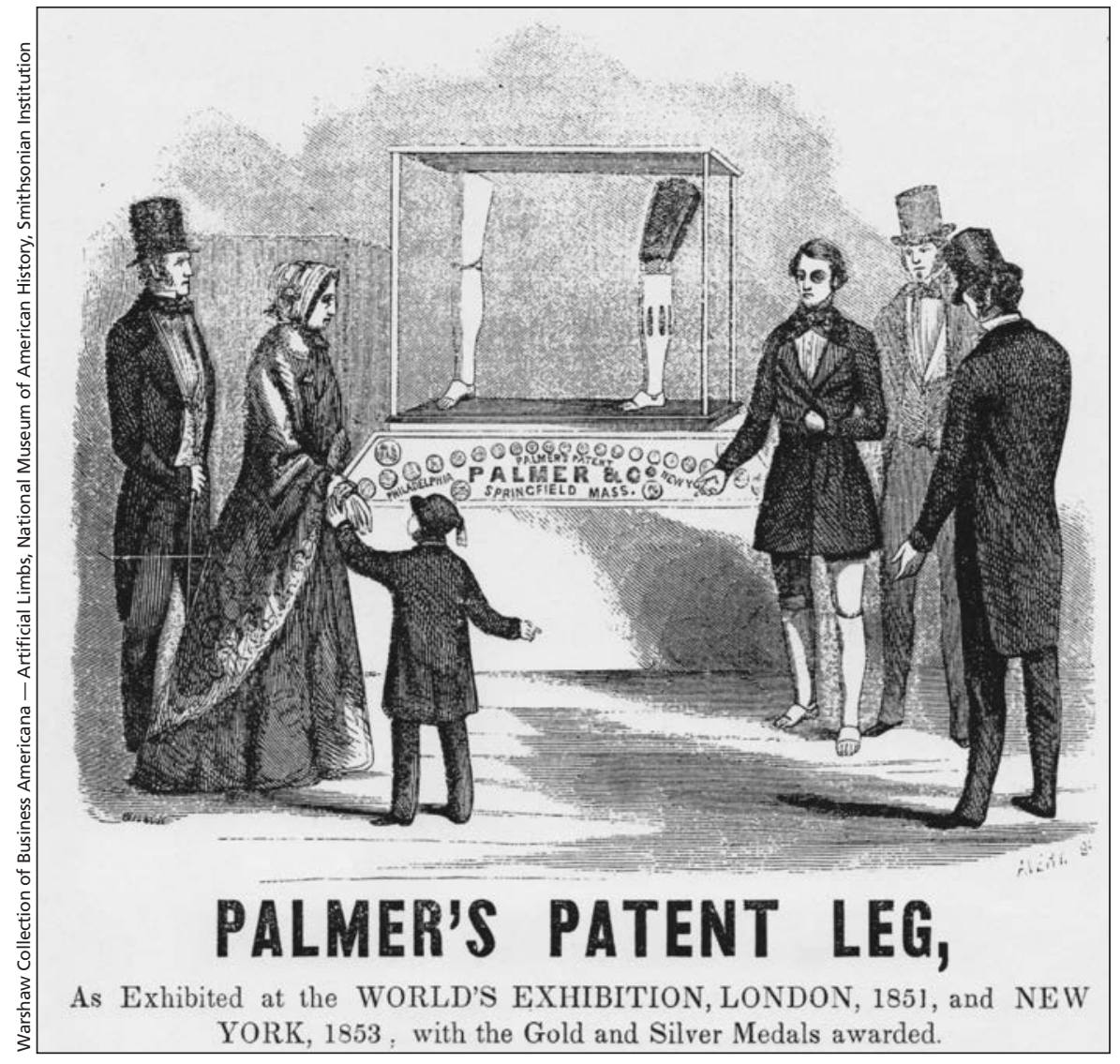

Figure 2: Advertisement for Palmer's Patent Leg, circa 1854.

extension, patients would be vulnerable to a product degraded through piracy and uncontrolled competition. The patent also allowed Palmer to continue his philanthropic practice of providing discounts to the indigent. Much like an ideal physician, Palmer was committed not only to the best science but also to the common good. "He seems to have regarded the invention as a sacred trust," Stansbury wrote sentimentally,

... placed in his hands for the relief of suffering humanity, and to have looked upon his own pecuniary interest in it as a consideration altogether secondary to the claims of the mutilated unfortunates who called to him for succor. ${ }^{7}$

Seemingly detached from self-interested profit, Palmer's patent, in this idealized rhetoric, was a testament to his benevolent professionalism. The physician and the artificial limb manufacturer stood in parallel roles of trust and authority, each supported by his own social contract. The doctor had his code of ethics, and Palmer had his patent.
Some physicians similarly argued that they should be permitted to harness the patent's power to serve both their own and the public good. For example, David Prince (a former vice-president of the AMA) and Thomas Antisell (a patent office examiner) reported on patenting in 1866 . They contended that patents not only made information about new inventions available for others to improve upon, but they also helped prevent the manufacture of dangerous imitations. Physicians deserved compensation for their useful ideas, and charity toward their fellow citizens could then follow. ${ }^{8}$

Similar arguments came up again over a century later. In the 1990s, the AMA articulated its opposition to patents for medical procedures, voicing familiar concerns that they might limit access to medical advances and put individual interests ahead of professionalism. ${ }^{9}$ At the same time, proponents contended that patents make information public and encourage innovation by making it financially worthwhile, ultimately improving the quality of medical care. ${ }^{10}$ In the end, the US restricted the ability of patentees to defend their medical procedure patents against infringement. Canada prohibits the patenting of medical treatment methods, although the field is still controversial, and many applicants try to reframe their innovations in terms that are eligible for patent protection.

As Palmer's case reminds us, the question of how best to balance innovation and its potential profits against ethics, professionalism and the public good is an old one, and it is not limited to physicians or pharmaceutical companies. Creative consideration of the many tools at our disposal -including codes of ethics, international agreements, legislation and patents themselves - will help ensure that we find this balance.

\section{Caroline Lieffers MA}

Program in the History of Science and Medicine, Yale University, New Haven, Conn.

\section{References}

1. Sanjuan JR. Statement by MSF on the official release of the full text of the Trans-Pacific Partnership trade agreement [news release]. 2015 Nov. 5. New York, Médecins Sans Frontières. Available: www.msfaccess.org/about-us/media-room/pressreleases/statement-msf-official-release-full-texttrans-pacific (accessed 2016 Apr. 7).

2. American Medical Association. Code of ethics of the American Medical Association, adopted May 1847. Philadelphia: T.K. and P.G. Collins; 1848:16.

3. Cassier M, Sinding C. 'Patenting in the public interest:' administration of insulin patents by the University of Toronto. Hist Technol 2008;24:153-71.

4. Douglas K, Jutras C. Patent protection for pharmaceutical products in Canada - chronology of significant events. PRB 99-46E. Ottawa: Parliamentary Information and Research Service; 2008 Available: www.parl.gc.ca/content/lop/research publications/prb9946-e.htm (accessed 2016 Apr. 7)

5. Palmer BF. Compensatory art. Bane and antidote a surgical adjuvant and reporter of artificial limbs. Philadelphia: Crissey \& Markely; 1859;8:12.

6. US Department of Commerce. US Patent Act. An act to promote the progress of useful arts, and to repeal all acts and parts of acts heretofore made for that purpose. Ch. 357, 5 Stat. 117. 1836 July 4.

7. Stansbury CF. Argument in behalf of the extension of the patent of B. Frank Palmer for an improvement in artificial legs, dated November 4th. 1846 before the Hon. Philip F. Thomas, Commissioner of Patents: hearing, 22d October, 1860. Baltimore: Murphy \& Co.; 1860:2.

8. Prince D, Antisell T. Patent rights among medical men. Trans Am Med Assoc 1866;17:521-8.

9. American Medical Association, Council on Ethical and Judicial Affairs. Ethical issues in the patenting of medical procedures. Food Drug Law J 1998;53:341-51.

10. Garris JJ. The case for patenting medical procedures. Am J Law Med 1996;22:85-108.

This article has been peer reviewed.

CMAJ 2016. DOI:10.1503/cmaj.150871 